Terakreditasi

Ditjen Penguatan Riset dan Pengembangan, Kemenristekdikti

Keputusan No: 21/E/KPT/2018, Tanggal 9 Juli 2018
Mei 2019, 6(2):138-145

DOI: http://dx.doi.org/10.33772/jitro.v6i2.5571

http://ojs.uho.ac.id/index.php/peternakan-tropis

\title{
Strategi Pengembangan dan Diversifikasi Sapi Potong di Jawa Timur
}

\author{
Soetriono $^{1 *}$, Djoko Soejono', Dimas B. Zahrosa', Ariq Dewi Maharani' ${ }^{1}$, Amam $^{2}$ \\ ${ }^{1}$ Program Studi Agribisnis, Jurusan Sosial Ekonomi Pertanian, Fakultas Pertanian, \\ Universitas Jember \\ ${ }^{2}$ Program Studi Peternakan, Jurusan Agronomi, Fakultas Pertanian, Universitas Jember \\ Jl. Kalimantan No.37, Kampus Tegalboto, Jember, Jawa Timur \\ *Email korespondensi: triono.faperta@unej.ac.id
}

(Diterima: 05-02-2019; disetujui 02-04-2019)

\begin{abstract}
ABSTRAK
Penelitian bertujuan untuk mengetahui peramalan populasi sapi potong, diversifikasi produk daging sapi potong, dan strategi pengembangan sapi potong di Jawa Timur. Penelitian dilakukan di Jawa Timur. Metode yang dipergunakan dalam kajian ini adalah metode deskriptif dan korelasional. Data yang digunakan dalam penelitian ini adalah data primer yang diperoleh dengan melakukan wawancara langsung dan FGD dan data sekunder yang diambil dari BPS, dinas terkait, buku-buku referensi, dan internet. Metode analisis data menggunakan analisis time series menggunakan metode Box-Jenkins (ARIMA) dengan Eviews, analisis nilai tambah dan analisis SWOT. Hasil yang diperoleh dari peramalan produksi sapi potong pada tahun 2017 hingga 2022 cenderung meningkat. Diversifikasi produk pengolahan sapi potong yaitu bakso dan abon daging. Hasil analisis nilai tambah, margin untuk keuntungan usaha bakso yaitu $22,18 \%$, lebih kecil daripada marjin pendapatan atau imbalan tenaga kerja yaitu $32,73 \%$. Margin untuk keuntungan industri usaha abon daging yaitu 23,12\%, lebih besar daripada marjin pendapatan atau imbalan tenaga kerja yaitu 18,29\%. Hasil analisis SWOT menunjukkan bahwa posisi kompetitif relatif dan berada pada kuadran SPEKULATIF dengan nilai IFAS 1,99 dan EFAS 3,72. Pengembangan sapi potong di Jawa Timur memiliki peluang yang prospektif akan tetapi produsen belum mampu mengembangkannya.
\end{abstract}

Kata Kunci : diversifikasi, populasi, spi potong, strategi pengembangan

\begin{abstract}
The purpose of this research was to forecast beef cattle population, diversification of beef products, and strategies of developing beef cattle in East Java. The study was conducted in East Java. The method used in this study was descriptive and co-relational methods. The data used in this study are primary data obtained by conducting direct interviews and FGDs; and secondary data taken from BPS, related agencies, reference books and the internet. The method of data analysis used was time series analysis using the Box-Jenkins (ARIMA) method with Eviews, value added analysis, and SWOT analysis. The results obtained from forecasting beef cattle production in 2017 to 2022 show increased trend. Diversification of beef processed products are meatballs (bakso) and meat floss (abon). The results of value added analysis showed the margin for the profit of the meatball business was $22.18 \%$, relatively smaller than the income margin or labor benefits, which was $32.73 \%$. The margin for the industrial profits of the shredded meat business was $23.12 \%$, which was greater than the income margin or labor benefit (18.29\%). The results of the SWOT analysis indicated that the relative competitive position is in the SPECULATIVE quadrant with IFAS value of 1.99 and EFAS 3.72. This means that beef cattle development in East Java has a prospective opportunity but producers have not been able to develop it.
\end{abstract}

Keywords: beef, diversification, development strategy, population 


\section{PENDAHULUAN}

Kondisi saat ini usaha sapi potong di Jawa Timur tumbuh dan berkembang di tengah-tengah kehidupan masyarakat. Upaya pemenuhan kebutuhan akan daging, khusunya daging sapi dapat dilakukan dengan cara pengembangan budidaya ternak sapi potong per skala rumah tangga. Usaha ternak sapi potong dapat dikatakan berhasil, apabila dapat memberikan kontribusi pendapatan dan dapat memenuhi kebutuhan hidup peternak sehari-hari. Hal ini dapat dilihat dari berkembangnya jumlah kepemilikan ternak, pertumbuhan berat badan ternak dan tambahan pendapatan keluarga. Pengelolaan sapi potong semakin menunjukkan peningkatan. Hal tersebut menyebabkan pertambahan jumlah populasi sapi potong di Jawa Timur yang mengalami peningkatan setiap tahunnya. Berikut data populasi sapi potong di Jawa Timur (Tabel 1).

Tabel 1. Populasi sapi potong di Jawa Timur tahun 2013-2016

\begin{tabular}{cc}
\hline Tahun & Populasi (ekor) \\
\hline 2013 & 3.949 .097 \\
2014 & 4.125 .333 \\
2015 & 4.267 .325 \\
2016 & 4.407 .807 \\
\hline
\end{tabular}

Sumber: Jawa Timur dalam angka

Sejalan dengan semakin meningkatnya pengelolaan usaha peternakan sapi potong dan jumlah populasinya, dibutuhkan diversifikasi produk olahan sapi potong. Hal tersebut diikuti dengan adanya bergesernya pola konsumsi masyarakat dalam mengkonsumsi produk olahan peternakan, terutama daging, dari mengkonsumsi daging segar menjadi produk olahan siap santap.

Tingginya tingkat konsumsi produk olahan peternakan merupakan suatu peluang usaha tersendiri untuk dikembangkan. Produk olahan daging tersebut bervariasi sehingga menimbulkan persaingan antar pengusaha/industry pengolahan sapi potong dan mendorong pengusaha untuk dikembangkannya teknologi dalam hal pengolahan daging. Industri olahan yang awalnya bersaing hanya pada tingkat lokal, maka harus pula bersaing dengan industri olahan dari luar daerah. Umumnya usaha pengolahan daging yang dilakukan oleh masyarakat dalam skala rumah tangga (home industry), masih menggunakan teknologi yang relatif sangat sederhana dengan pangsa pasar dari produk olahannya masih terbatas pada pasar lokal.

Implementasi yang bertahap namun berkesinambungan pada suatu perencanaan pengembangan sapi potong di Jawa Timur adalah kunci keberhasilan. Keluaran dari perencanaan adalah rancangan suatu pengembangan yang didukung dengan keadaan populasi sapi potong itu sendiri melalui peramalan dan mengetahui tingkat keuntungan dari diversifikasi sapi potong tersebut. Rencana aksi pengembangan dari sapi potong ditentukan melalui alternatif strategi pengembangan serta tahapan pengembangan kawasan tiap tahunnya.

\section{MATERI DAN METODE}

\section{Metode Penelitian}

Penentuan wilayah penelitian dilakukan secara sengaja (purposive) di wilayah Provinsi Jawa Timur karena memiliki potensi untuk pengembangan peternakan. Metode yang dipergunakan dalam kajian ini adalah metode deskriptif dan korelasional sedangkan teknik pelaksanaannya menggunakan teknik survei. Data yang digunakan dalam penelitian ini adalah data primer dan data sekunder. Data primer diperoleh dengan melakukan wawancara langsung dan dilakukan FGD. Pengumpulan data primer dilakukan pada beberapa wilayah yaitu di Kabupaten Bojonegoro, Tuban, dan Lamongan yang dapat mewakili kondisi peternakan di Jawa Timur. Data sekunder yang diambil dari BPS, dinas terkait, buku-buku referensi, dan internet.

\section{Analisis Data Penelitian}

Metode analisis data yang pertama menggunakan analisis time series menggunakan metode Box-Jenkins (ARIMA) dengan alat analisis Eviews. Metode Box-Jenkins (ARIMA) dapat dilakukan untuk mengetahui perkembangan populasi sapi potong di Jawa Timur pada tahun 2017 hingga 2022 dari data produksi masingmasing komoditas pada tahun 2002 hingga 2016.

Metode yang kedua menggunakan analisis nilai tambah.

$$
\mathrm{VA}=\mathrm{NP}-\mathrm{IC}
$$

Keterangan:

$\mathrm{VA}=$ Value added/ nilai tambah olahan komoditas pertanian ( $\mathrm{Rp} / \mathrm{kg}$ bahan baku) 
$\mathrm{NP}=$ Nilai produksi/olah yaitu penjualan hasil produksi ( $\mathrm{Rp} / \mathrm{kg}$ bahan baku)

IC =Intermediate Cost yaitu biaya-biaya yang menunjang dalam proses produksi (biaya bahan baku, peralatan dll) selain tenaga kerja ( $\mathrm{Rp} / \mathrm{Kg}$ bahan baku)

untuk mengetahui rasio nilai tambah digunakan formulasi sebagai berikut:

$$
\text { Rasio Nilai Tambah }=\frac{V A}{N P}
$$

untuk mengetahui keuntungan dari nilai tambah atau keuntungan dari imbalan modal dan manajemen dan imbalan tenaga kerja digunakan formulasi sebagai berikut:
a. $\pi=\mathrm{VA}-\mathrm{BTk}$
b. Tingkat Keuntungan $=\pi / \mathrm{VA} \times 100 \%$
c. Bagian Tenaga Kerja= BTk/VA x 100\%

Keterangan:

$\pi \quad=$ Nilai Keuntungan $(\mathrm{Rp} / \mathrm{Kg}$ Bahan Baku)

$\mathrm{VA}=$ Nilai Tambah (Rp/Kg Bahan Baku)

BTk = Biaya Tenaga Kerja (Rp/Kg Bahan Baku)

Metode analisis yang ketiga menggunakan analisis SWOT untuk mengetahui kekuatan dan kelemahan melalui nilai Internal Factor Analysis Summary (IFAS) dan peluang dan ancaman melalui nilai Eksternal Factor Analysis Summary (EFAS). Tindak lanjut dari identifikasi faktorfaktor internal dan eksternal adalah melakukan pembobotan terhadap permasalahan yang ada yang dapat dilihat pada Tabel 2. Pemilihan dan pembuatan strategi dilakukan pengawinan elemen internal dan eksternal dalam bentuk matriks SWOT yang dapat dilihat pada Tabel 3 .

Tabel 2. IFAS dan EFAS

\begin{tabular}{|c|c|c|c|c|}
\hline No & Uraian permasalahan & $\begin{array}{c}\text { Bobot } \\
\text { permasalahan }\end{array}$ & Rating & $\begin{array}{c}\text { Nilai } \\
\text { (Bobot x Rating) }\end{array}$ \\
\hline & $\begin{array}{c}\text { Kekuatan }(\mathrm{S}) \\
\text { Kelemahan }(\mathrm{W})\end{array}$ & 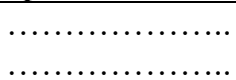 & ${ }^{\cdots}+\ldots \ldots \cdots \cdots$ & \\
\hline & Total nilai IFAS & ................... & $\ldots \ldots \ldots \ldots \ldots$ & $\ldots \ldots \ldots \ldots \ldots$ \\
\hline & $\begin{array}{l}\text { Peluang }(\mathrm{O}) \\
\text { Ancaman }(\mathrm{T})\end{array}$ & 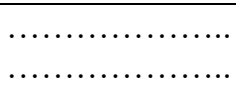 & 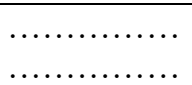 & ……… \\
\hline & Total nilai EFAS & $\ldots \ldots \ldots \ldots \ldots \ldots \ldots$ & $\ldots \ldots \ldots \ldots \ldots$ & $\ldots \ldots \ldots \ldots \ldots$ \\
\hline
\end{tabular}

Tabel 3. Matriks SWOT untuk menyusun strategi

\begin{tabular}{|c|c|c|}
\hline $\begin{array}{l}\text { IFAS } \\
\text { EFAS }\end{array}$ & Kekuatan (S) & Kelemahan (W) \\
\hline Peluang (O) & $\begin{array}{c}\text { Strategi SO } \\
\text { (Ciptakan startegi yang menggunakan } \\
\text { kekuatan untuk memanfaatkan } \\
\text { peluang) }\end{array}$ & $\begin{array}{c}\text { Strategi WO: } \\
\text { (Ciptakan strategi yang meminimalkan } \\
\text { kelemahan untuk memanfaatkan peluang) }\end{array}$ \\
\hline Ancaman $(\mathrm{T})$ & $\begin{array}{c}\text { Strategi ST } \\
\text { (Ciptakan startegi yang menggunakan } \\
\text { kekuatan untuk mengatasi ancaman) }\end{array}$ & $\begin{array}{l}\text { Strategi WT } \\
\text { (Ciptakan strategi yang meminimalkan } \\
\text { kelemahan dan menghindari ancaman) }\end{array}$ \\
\hline
\end{tabular}

\section{HASIL DAN PEMBAHASAN}

\section{Peramalan Populasi Sapi Potong di Jawa Timur}

Model yang telah terpilih digunakan untuk meramalkan produksi sapi potong dari tahun 2017 hingga 2022. Hasil yang diperoleh dari peramalan produksi sapi potong pada tahun 2017 hingga 2022 cenderung meningkat. Hasil peramalan ini sesuai dengan data yang digunakan dan nilai plot yang dihasilkan bahwa produksi sapi potong di Jawa Timur dengan menggunakan data tahunan dari tahun 2012 hingga 2016 cenderung meningkat. Hasil peramalan produksi sapi potong di Jawa Timur dapat dilihat pada Tabel 4. 
Tabel 4. Hasil peramalan produksi sapi potong di Jawa Timur tahun 2017-2022

\begin{tabular}{cc}
\hline Tahun & Produksi (ekor) \\
\hline 2017 & 4.549 .619 \\
2018 & 4.691 .394 \\
2019 & 4.833 .168 \\
2020 & 4.974 .943 \\
2021 & 5.116 .717 \\
2022 & 5.258 .492 \\
\hline
\end{tabular}

Sumber: Data sekunder diolah, 2017

Berdasarkan Tabel 4, dapat dilihat bahwa hasil peramalan populasi sapi potong di Jawa Timur tahun 2017 hingga 2022 cenderung

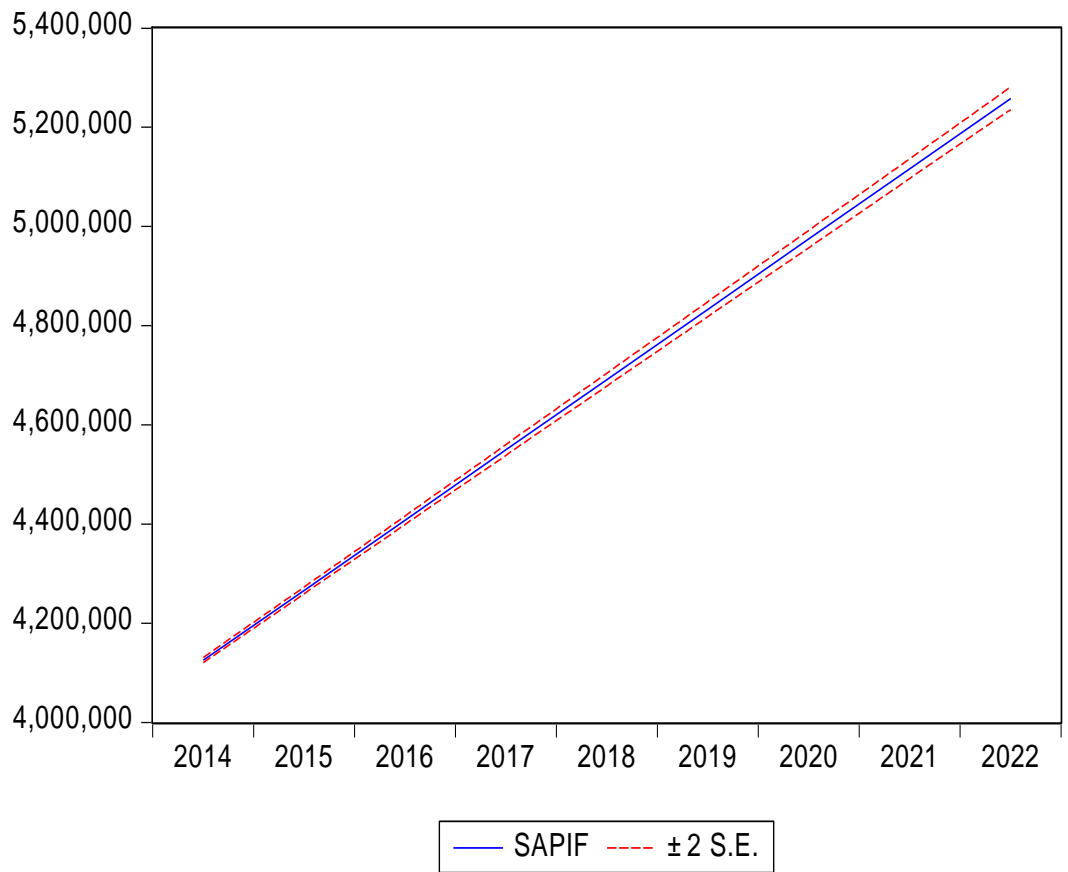

meningkat. Populasi sapi potong di Jawa Timur tahun 2017 adalah 4.549 .619 ekor meningkat di tahun 2018 menjadi 4.691 .394 ekor. Kenaikan populasi kembali terjadi pada tahun 2019 dan 2020 berturut-turut 4.833 .168 ekor dan 4.974 .943 ekor. Pada tahun 2021 dan tahun 2022 juga mengalami peningkatan populasi menjadi 5.116.717 ekor dan 5.258.492 ekor. Perkembangan populasi sapi potong di Jawa Timur dapat dilihat dari hasil grafik forecasting dari tahun 2012 hingga 2022 pada Gambar 1.

Gambar 1. Grafik perkembangan populasi sapi potong Jawa Timur

\section{Analisis Nilai Tambah Sapi Potong}

Peternakan sapi potong di Jawa Timur didominasi oleh peternakan rakyat.Sebagian besar peternak hanya memiliki sapi potong sebesar 1-4 ekor. Berdasarkan hasil Pendataan Sapi Potong, Sapi Perah dan Kerbau (PSPK 2011), populasi sapi potong di Jawa Timur sudah mampu memenuhi

\section{Forecast: SAPIF}

Actual: SAPI

Forecast sample: 20122022

Adjusted sample: 20142022

Included observations: 3

Root Mean Squared Error $\quad 742.5023$

Mean Absolute Error $\quad 453.5245$

Mean Abs. Percent Error $\quad 0.010628$

Theil Inequality Coefficient $8.70 \mathrm{E}-05$

Bias Proportion $\quad 0.332093$

Variance Proportion $\quad 0.001698$

Covariance Proportion $\quad 0.666209$ 


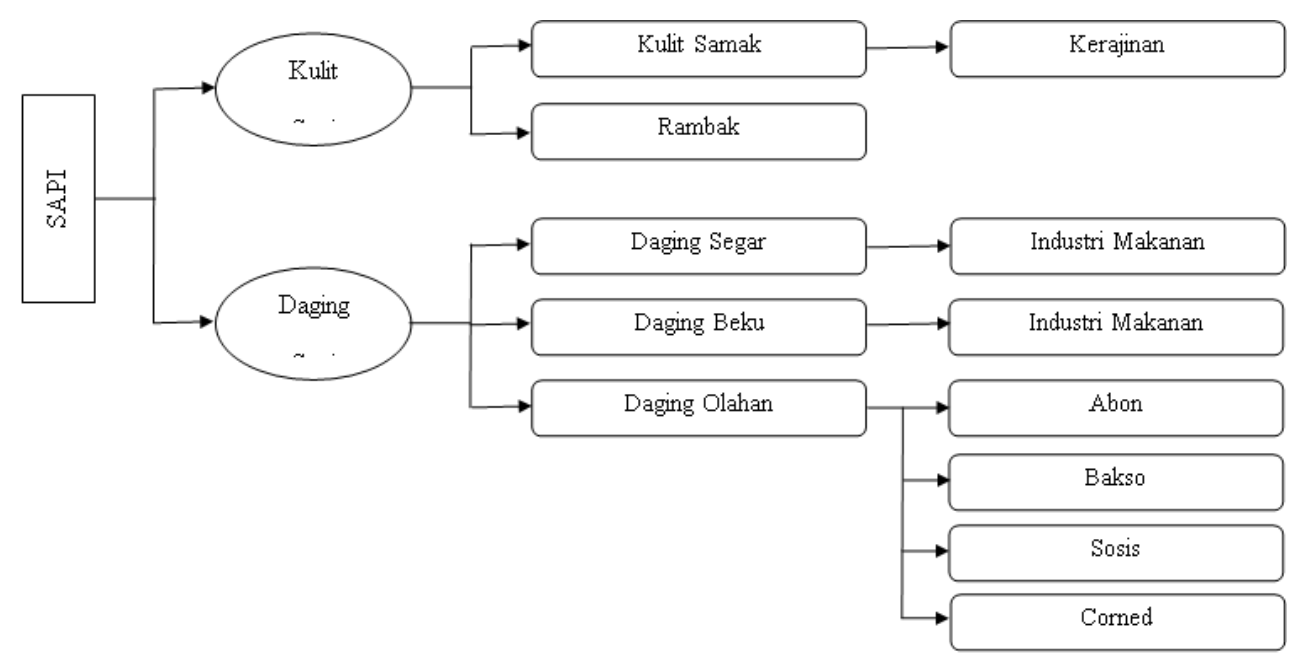

Gambar 2. Alternatif dan peluang industri sapi

Tabel 5. Perhitungan nilai tambah produk bakso dan abon

\begin{tabular}{|c|c|c|c|}
\hline \multirow{2}{*}{ No } & \multirow{2}{*}{ Komponen } & \multicolumn{2}{|c|}{ Produk } \\
\hline & & Bakso & Abon \\
\hline \multicolumn{4}{|c|}{ Output, Input dan Harga } \\
\hline 1 & Output (Kg/proses produksi) & 150 & 2 \\
\hline 2 & Input bahan baku ( $\mathrm{Kg} /$ proses produksi) & 50 & 5 \\
\hline 3 & Input tenaga kerja (jam/hari) & 3 & 1 \\
\hline 4 & Faktor konversi (1/2) & 3 & 0,4 \\
\hline 5 & Koefisien tenaga kerja $(3 / 2)$ & 0,06 & 0,2 \\
\hline 6 & Harga produk (Rp/Kg) & $50.000,00$ & $325.000,00$ \\
\hline 7 & Upah tenaga kerja $(\mathrm{Rp} / \mathrm{Kg})$ & $300.000,00$ & $32.000,00$ \\
\hline \multicolumn{4}{|c|}{ Penerimaan dan Keuntungan $(\mathrm{Rp} / \mathrm{Kg})$} \\
\hline 8 & Harga Input bahan baku & $95.000,00$ & $95.000,00$ \\
\hline 9 & Biaya intermediet & $24.801,73$ & $20.508,47$ \\
\hline 10 & Produksi $(4 * 6)$ & $150.000,00$ & $130.000,00$ \\
\hline \multirow[t]{2}{*}{11} & Nilai tambah (10-9-8) & $30.198,27$ & $14.491,53$ \\
\hline & Rasio nilai tambah \% (11/10) & 20,13 & 11,15 \\
\hline \multirow[t]{2}{*}{12} & Pendapatan tenaga kerja $(5 * 7)$ & $18.000,00$ & $6.400,00$ \\
\hline & Pangsa tenaga kerja $\%(12 / 11)$ & 59,61 & 44,16 \\
\hline \multirow[t]{2}{*}{13} & Keuntungan (11-12) & $12.198,27$ & $8.091,53$ \\
\hline & Rate keuntungan \% (13/10) & 8,13 & 6,22 \\
\hline \multicolumn{4}{|c|}{ Balas Jasa Pemilik Faktor Produksi } \\
\hline \multirow[t]{4}{*}{14} & Marjin (Rp/kg) & $55.000,00$ & $35.000,00$ \\
\hline & a. Pendapatan tenaga kerja langsung $(\%)$ & 32,73 & 18,29 \\
\hline & b. Sumbangan input lain (\%) & 45,09 & 58,60 \\
\hline & c. Keuntungan perusahaan (\%) & 22,18 & 23,12 \\
\hline
\end{tabular}

Sumber: Data diolah, tahun 2017 
Hasil analisis nilai tambah pengolahan komoditas sapi potong menjadi bakso dan abon daging dapat dilihat pada Tabel 5. Hasil analisa bentuk olahan sapi potong dapat dijelaskan di bawah ini.

Bakso. Bahan baku pembuatan bakso terdiri dari daging sebagai bahan baku utama dan bawang goreng, bawang putih, telur, garam, masako, merica, pengenyal, tapioka, penyedap, es batu, serta plastik untuk label sebagai bahan penunjang yang digunakan untuk mengolah bakso. Daging yang diolah untuk satu kali proses produksi sebanyak $50 \mathrm{~kg}$ yang dibeli dengan harga $\mathrm{Rp}$ 95.000,00 per kilogram. Pengolahan daging menjadi bakso memberikan nilai tambah yang positif dengan ditunjukkan dari nilai tambah yang lebih dari satu yaitu sebesar Rp 30.198,27 per kilogram bahan baku, artinya penerimaan pengusaha setiap mengolah satu kilogram daging menjadi bakso sebesar Rp 30.198,27. Sedangkan keuntungan yang didapatkan ketika bakso sudah terjual dipasaran adalah sebesar Rp 12.198,27 per kilogram bahan baku, yang artinya dengan keseluruhan biaya yang dikeluarkan selama proses produksi pemanfaatan daging dalam pembuatan bakso adalah menguntungkan.

Berdasarkan analisis nilai tambah, diperoleh marjin dari pengolahan bakso sebesar $\mathrm{Rp}$ 55.000,00 per kilogram. Marjin ini merupakan selisih harga atau nilai produksi sebesar $\mathrm{Rp}$ $150.000,00$ per kilogram dengan nilai input atau harga bahan baku sebesar Rp 95.000,00 per kilogram. Marjin ini kemudian didistribusikan menjadi imbalan tenaga kerja, sumbangan input lain, dan juga keuntungan perusahaan atau industri. Marjin yang didistribusikan untuk tenaga kerja adalah sebesar $\mathrm{Rp} 18.000,00$ per kilogram atau sebesar 32,73 persen. Marjin untuk sumbangan input lain sebesar $\mathrm{Rp} 24.801,73$ per kilogram atau 45,09 persen. Sedangkan marjin untuk keuntungan perusahaan atau industri sebesar Rp 12.198,27 per kilogram atau 22,18 persen, yang merupakan imbalan bagi perusahaan atau industri atas penggunaan modal, aktiva dan manajemen. Berdasarkan distribusi marjin keuntungan perusahaan atau industri tersebut didapatkan kesimpulan bahwa margin untuk keuntungan perusahaan atau industri lebih kecil daripada marjin pendapatan atau imbalan tenaga kerja. Dalam hal ini pengusaha bakso lebih mementingkan keuntungan pendapatan atau imbalan tenaga kerja dari pada perusahaan atau industrinya.

Abon Sapi. Bahan baku pembuatan abon terdiri dari daging sebagai bahan baku utama dan minyak goreng, bawang merah, bawang putih, jahe, garam, gula, kunyit, kencur, penyedap, lombok besar serta plastik untuk label sebagai bahan penunjang yang digunakan untuk mengolah abon. Daging yang diolah untuk satu kali proses produksi adalah sebanyak $5 \mathrm{~kg}$ yang dibeli dengan harga Rp 95.000,00 per kilogram. Pengolahan daging menjadi abon memberikan nilai tambah yang positif dengan ditunjukkan dari nilai tambah yang lebih dari satu yaitu Rp 14.491,53 per kilogram bahan baku, artinya penerimaan pengusaha setiap mengolah satu kilogram daging menjadi abon sebesar Rp 14.491,53. Sedangkan keuntungan yang didapatkan ketika abon sudah terjual dipasaran sebesar Rp 8.091,53 per kilogram bahan baku, yang artinya dengan keseluruhan biaya yang dikeluarkan selama proses produksi pemanfaatan daging dalam pembuatan abon adalah menguntungkan.

Berdasarkan analisis nilai tambah ini diperoleh marjin dari pengolahan abon sebesar Rp 35.000,00 per kilogram. Marjin ini merupakan selisih harga atau nilai produksi sebesar $\mathrm{Rp}$ $130.000,00$ per kilogram dengan nilai input atau harga bahan baku sebesar Rp 95.000,00 per kilogram, marjin ini kemudian didistribusikan menjadi imbalan tenaga kerja, sumbangan input lain, dan juga keuntungan perusahaan atau industri. Marjin yang didistribusikan untuk tenaga kerja sebesar Rp 6.400,00 per kilogram atau 18,29 persen. Marjin untuk sumbangan input lain sebesar Rp 20.508,47 per kilogram atau 58,60 persen. Sedangkan marjin untuk keuntungan perusahaan atau industri sebesar $\mathrm{Rp} 8.091,53$ per kilogram atau 223,12 persen, yang merupakan imbalan bagi perusahaan atau industri atas penggunaan modal, aktiva dan manajemen. Dari hasil distribusi marjin keuntungan perusahaan atau industri tersebut didapatkan kesimpulan bahwa margin untuk keuntungan perusahaan atau industri lebih besar daripada marjin pendapatan atau imbalan tenaga kerja, dalam hal ini pengusaha abon lebih mementingkan keuntungan perusahaan atau industrinya daripada pendapatan atau imbalan tenaga kerja. 


\section{Strategi Pengembangan Sapi Potong di Jawa Timur}

Hasil Analisis SWOT terhadap Kekuatan, Kelemahan, Peluang dan Ancaman Pengembangan sapi potong di Jawa Timur, nilai IFAS pada faktor kekuatan didapatkan nilai tertinggi sebesar 0,18 yaitu faktor setiap wilayah memiliki Rumah Pemotongan Hewan (RPH) dan Tempat Pemotongan Hewan (TPH). Sementara itu, faktor kelemahan diperoleh nilai tertinggi sebesar 0,24 yaitu faktor ternak sebagai usaha sambilan dan kondisi kandang ternak sapi belum dikelola dengan baik. Nilai EFAS pada faktor peluang diperoleh nilai tertinggi sebesar 0,32 yaitu faktor permintaan dan kebutuhan daging meningkat. Faktor ancaman, didapatkan nilai tertinggi sebesar 0,32 yaitu faktor data riil populasi ternak belum akurat, masuknya produk daging secara illegal dan jumlah RPH terstandarisasi sedikit. Hasil diagram matrik analisis SWOT menunjukkan bahwa posisi kompetitif relatif dan berada pada kuadran SPEKULATIF dengan nilai IFAS 1,99 dan EFAS 3,72. Hal ini berarti Pengembangan Sapi Potong di Jawa Timur memiliki peluang yang prospektif akan tetapi produsen belum mampu mengembangkannya. Berdasarkan matrik SWOT, diperoleh beberapa alternatif strategi antara lain:

1. Fasilitasi pembiayaan dengan pendampingan yang ketat dan terarah;

2. Peningkatan kualitas lahan guna menjamin ketersediaan pakan;

3. Melakukan pemetaan potensi ternak dan kondisi RPH dan fasilitas pendukung lainnya;

4. Mendorong pengusa-haan ternak sapi secara terintegrasi guna mene-kan biaya produksi melalui penguatan kelompok;

5. Penegakan aturan main;

6. Melakukan proteksi terhadap kawasan sentra pengembangan;

7. Mengembangkan industri melalui regulasi pemerintah;

8. Pelaku agribisnis perlu menentukan keseimbangan permintaan dan penawaran;

9. Perketat pemeriksaan teknis terhadap produk daging yang masuk;

10.Menetapkan kuota impor daging sapi secara kontinyu.

Berdasarkan beberapa pilihan alternatif tersebut, ditentukan prioritas strategi yaitu (1) mendorong pengusahaan ternak sapi secara terintegrasi guna menekan biaya produksi melalui penguatan kelompok; (2) penegakan aturan main; (3) melakukan proteksi terhadap kawasan sentra pengembangan; dan (4) mengembangkan industri melalui regulasi pemerintah.

Tahapan pengembangan sapi potong di Jawa Timur mulai dari hulu sampai hilir dan pendukungnya yang dapat dilakukan untuk 5 tahun kedepan yaitu antara lain:

1. Tahun pertama dilakukan penyediaan bibit pejantan sapi terseleksi dan induk yang terstandirisasi khas sapi Jawa Timur dan penyediaan bahan dan alat gertak birahi dan inseminasi buatan;

2. Tahun kedua dilakukan optimalisasi lahan sumber pakan (sawah, tegal, kebun, ladang, dll dan tersedianya bibit rumput unggul dan lahan tempat produksi pakan ternak serta membangun insfrastruktur pengairan untuk hijauan makanan ternak;

3. Tahun ketiga peningkatan kapasitas dan produktifitas (anak sapi lahir hasil IB) inseminator dari rata-rata 50 ekor menjadi minimal 500 ekor per inseminator dan sertifikasi ternak untuk menjamin kemanan ternak;

4. Tahun keempat dilakukan Sertifikasi ternak untuk menjamin keamanan ternak dam mengoptimalkan fungsi RPH untuk memproduksi daging sapi yang ASUH;

5. Tahun kelima dilakukan Mengoptimalkan fungsi RPH untuk memproduksi daging sapi yang ASUH dan mendorong tumbuhnya industry pengolahan daging serta membentuk sentra-sentra peternakan rakyat (SPR) pada kawasan-kawasan pengembangan yang telah ditetapkan.

Tahapan tersebut harus didukung dengan peningkatan kualitas sumberdaya manusia, pengembangan kelembagaan pelayanan peternakan, penguatan pemasaran hasil sapi potong tersbeut dan peningkatan kemitraan dengan perusahaan pemerintah maupun swasta.

\section{KESIMPULAN}

Peramalan produksi sapi potong pada tahun 2017 hingga 2022 cenderung meningkat. Diversifikasi produk sapi potong menjadi bakso dan abon memberikan keuntungan berupa: (a) margin untuk keuntungan usaha bakso adalah $22,18 \%$, lebih kecil dari pada marjin pendapatan 
atau imbalan tenaga kerja yaitu $32,73 \%$, (b) margin untuk keuntungan industri usaha abon daging adalah $23,12 \%$, lebih besar dari pada margin pendapatan atau imbalan tenaga kerja yaitu $18,29 \%$. Hasil analisis SWOT menunjukkan bahwa posisi kompetitif relatif dan berada pada kuadran SPEKULATIF dengan nilai IFAS 1,99 dan EFAS 3,72 . Pengembangan sapi potong di Jawa Timur memiliki peluang yang prospektif akan tetapi produsen belum mampu mengembangkannya.

\section{DAFTAR PUSTAKA}

Abdullah, A. \& H. Ibrahim. 2014. Persepsi peternakan terhadap kinerja penyuluhan dalam pengembangan teknologi pengolahan jerami padi dan limbah ternak sapi potong. JITRO 1(1):99-107.

Ananta, A., H. Hafid, \& L.O.A. Sani. 2015. Faktor-faktor yang mempengaruhi produktivitas usaha ternak sapi bali pada peternak transmigran dan non transmigran di Pulau Kabaena Kabupaten Bombana. JITRO 2(3):52-67.

Direktorat Jenderal Peternakan dan Kesehatan Hewan. 2016. Laporan Tahunan DITJEN PKH 2016. Direktorat Jenderal Peternakan dan Kesehatan Hewan. Jakarta.

Habib S. 2008. Strategi Pengembangan Usaha Bakso. Rajawali Press. Jakarta.

Hasiruddin, H. Hafid \& L. Malesi. 2015. Potensi dan kelayakan finansial usaha peternakan sapi potong di Desa Alebo Kecamatan Konda Kabupaten Konawa Selatan. JITRO 2 (3):88-105.

Indrayani, I. \& J. Hellyward. 2015. Optimalisasi produksi dan maksimalisasi keuntungan usaha ternak sapi potong dengan sistem integrasi sapi-sawit di Kabupaten
Dharmasraya. Jurnal Peternakan Indonesia 17(3):187-194.

Kusriatmi, R. Oktaviani, Y. Syaukat, \& A. Said. 2014. Peranan teknologi inseminasi buatan (IB) pada produksi sapi potong di Indonesia. Jurnal Agro Ekonomi 32(1):57-74.

Malotes, J. 2016. Strategi .pengembangan usaha peternakan sapi potong di Kecamatan Tinakung Utara Kabupaten Banggai Kepulauan. Jurnal Agroland 23(3):198-207.

Moleong, L.J. 2007. Metodologi Penelitian Kualitatif. Rosdakarya. Bandung

Nurjayanti, E. Dewi, Darsono, \& S. Supardi. 2012. Dinamika dan model ARIMA penawaran beras di Kabupaten Sukoharjo sebelum dan selama pPelaksanaan otonomi daerah. MEDIAGRO 8(1):61-71.

Otoluwa, M.A., A.H.S. Salendu, A.K. Rintjap, \& M.T. Massie. 2016. Prospek pengembangan usaha ternak sapi potong di Kecamatan Bolangitang Timur Kabupaten Bolaang Mongodow Utara. Jurnal Zootek 36(1):191197.

Rangkuti, F. 2013. SWOT Balanced Scorecard. Gramedia Pustaka Utama. Jakarta.

Rosita, F., H. Hafid, \& R. Aka. 2015. Susut Masak dan Kualitas Organoleptik Bakseo Daging Sapi dengan penambahan Tepung Sagu pada Level yang Berbeda. JITRO 2(1):7-14.

Siregar \& N. Ilham. 2013. Upamya Peningkatan Efisiensi Usaha Ternak Ditinjau dari Aspek Agribisnis yang Berdaya Saing. Forum Penelitian Agro Ekonomi 21(1):57-66.

Yusuf, A., H. Hafid, \& A.M. Tasse. 2016. Analisis pendapatan pedagang bakso sapi di Kabupaten Kolaka. JITRO 3(3):57-66. 